\title{
E-ducar o olho e o olhar: narrativas audiovisuais, contextos escolares e estágios curriculares supervisionados ${ }^{1}$
}

\author{
Valéria Cazetta ${ }^{2}$ \\ Celi Rodrigues Chaves Dominguez² \\ Fabiana Curtopassi Pioker-Hara² \\ Josely Cubero ${ }^{2}$
}

\section{Resumo}

Este trabalho insere-se em um projeto investigativo no campo das culturas profissionais docentes, com a finalidade de pensar sobre processos de (re)construção de identidades docentes que ocorrem durante os cursos de formação inicial de professores, especialmente professores em formação, da graduação em licenciatura em ciências da natureza da Escola de Artes, Ciências e Humanidades da Universidade de São Paulo (EACH-USP), no período em que realizam atividades de estágios obrigatórios nas escolas. Solicitou-se aos/às estudantes-estagiários/as a elaboração de narrativas audiovisuais que dessem a ver aspectos observados por eles durante o acompanhamento de interações ocorridas em situações de sala de aula. A aposta teórica deu-se em dois flancos: a educação do olhar e a educação do olho, com o intuito de desnaturalizar e desconstruir miradas em curso na contemporaneidade por diferentes ordens discursivas acerca das escolas. Como hipótese de pesquisa, supomos que, ao se alterar o tipo de linguagem empregada na produção discursiva, modifica-se a educação do olhar via educação do olho, possibilitando que topografias invisíveis, como processos de ensino e aprendizagem, ganhem visibilidade plástica por meio da linguagem audiovisual. Os curtas-metragens foram analisados por meio das múltiplas linguagens empregadas: corporal, verbal, visual e sonora, mobilizando, nesses professores em formação, diferentes maneiras de apresentar como vivenciam o momento de sua formação. Conclui-se que a imersão dos/as estudantes-estagiários/as em uma mesma escola, durante mais de um semestre e meio, até o momento de produção do audiovisual, possibilitou-lhes desnaturalizar concepções do que possa ser a escola pública a partir de suas experiências com a produção de curtas-metragens.

\section{Palavras-chave}

Identidades docentes - Culturas profissionais - Audiovisuais - Cinema - Estágio supervisionado.

1- Pesquisa financiada pela Fundação de Amparo à Pesquisa do Estado de São Paulo (FAPESP), processo 2015/06329-0 (vigência 01/08/2015 a 31/07/2017), sob coordenação da profa. dra. Luciana Maria Viviani (EACH-USP).

2- Escola de Artes e Ciências Humanas (EACH), Universidade de São Paulo, São Paulo, SP, Brasil. Contatos: vcazetta@usp.br; celi@usp.br; fpioker@usp.br; josely@usp.br 


\section{E-ducate the eye and the gaze: audiovisual narratives, school context and supervised curricular internships}

\section{Abstract}

This text is part of an investigative project in the field of teacher professional cultures. It aims at thinking about the processes of (re)construction of teacher identities that take place during the initial teacher training courses, especially among the teachers-to-be who are undergoing training in the Teacher's Training Degree in Nature Sciences at the School of Arts, Sciences and Humanities of University of São Paulo (EACH-USP). During this period, the students carry out compulsory internship activities in schools. We asked the intern/students to elaborate audiovisual narratives that would unveil aspects of the interactions observed in classroom situations. The theoretical stake opened up two fronts: the education of the eye and the education of the gaze, aiming at the denaturalisation and deconstruction of contemporary gazes by encouraging different discursive orders about the schools. As a research hypothesis, we suppose that, as the type of language employed in the discursive production is changed, also changed is the education of the gaze via the education of the eye, allowing for invisible topographies, such as the processes of teaching and learning, to gain visibility by means of audiovisual language. The short films were analysed in the multiple languages employed: body, verbal, visual and sound, mobilising, in the students/interns, different ways of presenting how they lived the moment of their training. The conclusion is that the immersion of the interns/students in a single school, during one semester and a half, up until the production moment of the audiovisual piece, allowed them to experience the denaturalisation of concepts about what a state public school might be, grounded on their experiences with the production of short films.

\section{Keywords}

Teacher identities - Professional cultures - Audiovisuals - Cinema - Supervised internship.

\section{Introdução}

Vivemos sob o jugo de um excesso de imagens? De maneira alguma. A demasia reside no fato de que o sistema de informação "funciona selecionando seres que falam e raciocinam, que são capazes de 'descriptar' a vaga de informações referentes às multidões anônimas” (RANCIÈRE, 2012, p. 94 [2009, p. 96]). 0 que há de questionável é o tipo de padrão empregado nas edições das imagens, palavras e sons, mesmo porque, segundo Jacques Rancière (2012, p. 96 [2009, p. 99]): 
[...] uma imagem nunca está sozinha. Pertence a um dispositivo de visibilidade que regula o estatuto dos corpos representados e o tipo de atenção que merecem. A questão é saber o tipo de atenção que este ou aquele dispositivo provoca.

Decidimos iniciar o texto partindo do parágrafo acima para preparar o chão a ser percorrido pelo leitor na jornada dos/as estudantes-estagiários durante a elaboração de narrativas audiovisuais em seus estágios obrigatórios. Na esteira de Alfredo Bosi, Carlos Miranda (2001) faz distinção entre educação do olhar e educação do olho. A primeira diz respeito à "educação do movimento interno do ser" (p. 29), tributária de reflexões da literatura no campo educacional, referindo-se tanto à importância do acesso dos/ das estudantes à diversidade de produtos gerados pela indústria cultural, bem como à criação de metodologias de ensino no emprego de imagens e sons em movimento, seja na educação básica ou no ensino superior.

Ainda de acordo com Miranda (2001, p. 29) “a expressão ‘Educação do Olhar’ tornouse, portanto, moeda corrente nos textos que pretendem abordar, em geral, as relações entre escola e cultura". A educação do olho, por sua vez, afasta-se da preocupação pedagógica à medida que problematiza a produção de imagens e sons:

[...] como parte de um programa de educação visual, que é anterior ao desenvolvimento tecnológico da produção industrial de imagens [...]. Por Educação do Olho estamos tentando pensar origens históricas da produção industrial da cultura, considerando esta última como parte de um programa estético/político mais amplo do que o momento de sua configuração industrial. Tal programa antecede ao desenvolvimento tecnológico do século XIX, necessário para a consolidação da cultura industrial. (MIRANDA, 2001, p. 29-30).

Ao mobilizar tal distinção, Miranda teve como finalidade perceber a especificidade do século XIX em relação ao olho e ao olhar, a saber, o olhar por meio de aparelhos. De acordo com esse autor, a novidade daquele século refere-se à:

[...] possibilidade de produzir e reproduzir imagens a partir de aparelhos, inclusive de forma e em escala industrial [...]. Afınal, é o século da fotografia e do cinema e, podemos dizer, o da construção da indústria das imagens e sons em movimento. (MIRANDA, 2001, p. 30).

Interessante o destaque para aquilo que diz respeito às transformações nas "formas de visibilidade do real que o olhar dos aparelhos provoca” (MIRANDA, 2001, p. 30), porque essas mudanças não são apenas o resultado de uma possibilidade tecnológica, mas, sobretudo, são "parte de um projeto de educação visual mais amplo, que pode nos remeter à perspectiva Renascentista e ao “olhar' cartesiano” (MIRANDA, 2001, p. 31).

Jan Masschelein (2008), por sua vez, advoga em prol da importância do educar o olhar, não como educare (ensinar), mas "e-ducere: conduzir para fora, dirigir-se para fora, levar para fora" (p. 36), de modo que "e-ducar o olhar não significa adquirir uma visão crítica ou liberada [...], mas sim nos tornarmos atentos, significa prestar atenção” (p. 36), entendendo-a como abertura de "espaço para uma possível autotransformação" (p. 36). 
Ou seja: "e-ducar o olhar requer uma prática de pesquisa crítica que realize uma mudança prática em nós mesmos e no presente em que vivemos, e não uma fuga dele (em direção a um futuro melhor)" (MASSCHELEIN, 2008, p. 36).

Práticas que nos interpelem a ir para a rua, que nos movimentem, que nos desloquem, que permitam nossa exposição. E-ducar o olhar, para o autor, pode significar um convite a caminhar, pois, ao caminharmos, deslocamos nosso olhar e esse movimento possibilita a experiência, "não apenas como vivência passiva (de ser comandada), mas também como uma espécie de trilha na passagem pela estrada” (MASSCHELEIN, 2008, p. 37).

0 ato de caminhar não se vincula, necessariamente, ao mudar o corpo de posição geográfica, mas, sobretudo, abalar essa posição corpórea, pô-la em jogo, deixá-la fora de posição, de maneira que as geografias das estradas nos conduzam, nos comandem. Este comando não se refere ao "poder de um tribunal, não é a imposição de uma lei ou princípio [...], mas sim a manifestação (aprendizado) de uma força que nos põe em movimento e assim abre o caminho", impulsionando-nos "para que nos desloquemos de onde (quem) estamos (somos)" (MASSCHELEIN, 2008, p. 39). A força da estrada ${ }^{3}$ que nos arrasta, nos arrebata, conduzindo-nos para fora. Outras paragens, outras passagens.

Interessou-nos realizar um exercício com os/as estudantes-estagiários/as da graduação em licenciatura em ciências da natureza da Escola de Artes, Ciências e Humanidades da Universidade de São Paulo (EACH-USP), de maneira a possibilitar, via produção de narrativas audiovisuais, a criação de espaçamentos educativos por meio da prática do caminhar como exercício de estar atento, deixando que as topografias invisibilizadas das escolas comandassem as câmeras filmográficas.

Trata-se de espaçamentos, topografias outras, rugosidades quase imperceptíveis, pequenos nadas que compõem a força das estradas a evidenciar fronteiras tênues produzidas por abalos, amiúde, imperceptíveis. Sismos entre uma educação do olhar, uma educação do olho e o e-ducar o olhar - constituintes de dispositivos de visibilidades. Mobilização feita pelos/as estudantes-estagiários/as ao partilharem um senso comum - entendido aqui:

[...] como uma comunidade de dados sensiveis: coisas cuja visibilidade considera-se partilhável por todos, modos de percepção dessas coisas e significados também partilháveis que lhe são conferidos. (RANCIÈRE, 2012, p. 99 [2009, p. 102]).

0 dispositivo de visibilidade, para esse autor, nada mais é do que um senso comum, isto é, "um dispositivo espaço-temporal dentro do qual palavras e formas visíveis são reunidas em dados comuns, em maneiras comuns de perceber, de ser afetado e dar sentido" (RANCIĖRE, 2012, p. 99 [2009, p. 102]), ou seja, todos nós temos capacidade de sentir e de aprender.

Operamos, então, uma sobreposição da educação do olhar, da educação do olho, e do e-ducar o olhar, com o propósito de fazer com que professores/as em formação inicial

3- A palavra estrada poderia, aqui, ser substituída pela noção de arquivo, em uma acepção foucaultiana (FOUCAULT, 2013 [1972]). A seleção dos materiais/documentos (imagens, filmes, livros, HQs etc.), os tais "arquivos mortos" ou arquivos permanentes, se transformados em arquivo, podem ganhar outra vida. Nesse sentido, o arquivo trata deste paradoxo entre nossa morte (anunciada) e a nossa vida (presentificada). Se não deixa nada é como se não tivesse havido vida e morte de algo/alguém. 
experimentassem ultrapassar a figuração: o ilustrativo e o narrativo (DELEUZE, 2007). Como estagiários/as, espera-se que esses/as graduandos/as em licenciatura deixem de ser observadores/as alheios/as ao contexto escolar para serem agentes imersos/as no dia a dia da escola. Dessa forma, o exercício proposto foi problematizar o olhar pré-concebido sobre a instituição escolar e fazer com que esses/as professores/as em formação experimentassem a escola por meio de informações em imagens e sons (ALMEIDA, 2004) não mais sobre ela, mas com as pessoas que a animam desde suas próprias vivências, ou seja, fazê-los/as olhar para a escola por dentro dela mesma. Uma vez imersos/as no contexto escolar, a escolha das imagens por parte dos/as estagiários/as constituiu parte de narrativas audiovisuais por eles/as construídas com os/as alunos/as, professores/as e funcionários/as da escola. Esses/ as estudantes realizaram uma imersão nas escolas - seus espaços, suas pessoas, seu tempo - onde estagiavam, buscando não encontrar a imagem certa para acolher e compor com a narrativa audiovisual à referida instituição, mas sim selecionar e editar imagens e sons para, assim, ficcionarem a composição de uma escola outra.

Acreditamos que esse exercício de imersão na instituição escolar, por meio da educação do olhar, leva o/a estagiário/a a pensar sobre seu próprio papel dentro daquele que será seu campo profissional contribuindo, assim, para a tomada de consciência de sua própria identidade profissional que está sendo formada.

Para Maurice Tardif (2002), a complexidade é marca do processo de formação de um/a professor/a, dada a multiplicidade de fatores que convergem para seu desenrolar, desde a experiência e vivência pessoal e profissional ao contato com diferentes espaços culturais e fontes de socialização, entre outros. Como lembra Claude Dubar (2005, p. 136):

[...] a identidade nada mais é que o resultado a um só tempo estável e provisório, individual e coletivo, subjetivo e objetivo, biográfico e estrutural, dos diversos processos de socialização que, conjuntamente, constroem os indivíduos e definem as instituições.

Acreditamos que o olhar para a instituição escolar a partir da construção de uma narrativa audiovisual possa servir de ponte de ligação entre múltiplos fatores que representam a escola e o ser professor/a, levando o/a estagiário/a a problematizar a própria formação docente. Nessa perspectiva, debruçamo-nos sobre as produções das narrativas audiovisuais dos/as estagiários/as visando a responder às perguntas: ao construírem uma narrativa audiovisual acerca da escola campo, para onde se dirigem os olhares dos futuros professores? Quais são as experiências e conflitos que emergem das construções dessas narrativas? Que linguagens e metáforas são utilizadas para superar desafios técnicos na construção da narrativa?

Nossa hipótese é: quando se muda o tipo de linguagem empregada na produção discursiva altera-se a educação do olhar via educação do olho, fazendo com que os esquemas sensórios-motores - que sempre nos ligam às representações orgânicas do que significa aprender - sejam interceptados por forças outras. Isso mobilizou nos/as estagiários/as a suspensão do tempo cronológico para outro tempo: aquele do acontecimento - impossível de ser representado, capturado. Apresentamos a seguir o que entendemos por narrativas audiovisuais para que possamos delinear nossos procedimentos metodológicos. 


\section{Das narrativas audiovisuais}

Para apresentar aos/as nossos/as alunos/as a solicitação acerca da realização das narrativas audiovisuais sobre a escola onde estagiavam, inspiramo-nos em uma das pistas metodológicas apresentadas por Rancière em $O$ espectador emancipado, a saber:

[...] o problema não é opor a realidade a suas aparências. É constituir outras realidades, outras formas de senso comum [...], outros dispositivos espaciotemporais, outras comunidades de palavras e coisas, formas e significados. (RANCIÈRE, 2012, p. 99 [2009, p. 102]).

Nesse sentido, as abordagens de João Moreira Salles (2005) e Arthur Omar (1978) acerca dos documentários foram importantes, porque ambos os autores desnaturalizaram a produção desse tipo de linguagem cinematográfica, situando-a como tributária da ficção narrativa, de modo que o objeto de sua construção é muito similar ao do filme ficcional.

Salles (2005) afirma que o documentário pode ser muitas coisas, dentre elas: "produto das empresas e instituições que fazem documentários" (p. 60); "a maneira como o espectador vê o filme" (p. 60); "um determinado tipo de retórica” (p. 65). Ele ainda considera que todo documentário tem duas naturezas distintas: trata-se do "registro de algo que aconteceu no mundo" (p. 64) e de uma "retórica construída a partir do que foi registrado" (p. 64). Para este autor há uma fórmula tradicional acerca do documentário: "eu falo sobre vocês para eles. Existe o documentarista, (eu), existe o personagem, (você), e existem eles, os espectadores” (p. 67). Os personagens, para Salles, são inúmeros, entretanto, a pessoa filmada é uma só.

Omar (1978), por sua vez, afirma que o filme documentário não existe como linguagem autônoma e aquilo que chamamos documentário "é um sub-produto da ficção narrativa, sem conter em si qualquer aparato formal e estético que lhe permita cumprir com independência seu hipotético programa mínimo: documentar” (p. 406). Além disso, "para haver documentário, é preciso uma exterioridade do sujeito e do objeto [...]. Só se documenta aquilo de que não se participa" (p. 410). Para o autor, poderiam surgir "espécies de antidocumentários que se relacionariam com seu tema de um modo mais fluido e constituiriam objetos em aberto para o espectador manipular e refletir" (p. 408).

Com isso, Omar não está dizendo que o documentário não existe, mas advoga em prol da ideia de que "o modo de aparecer do seu objeto, o modo de construir a existência desse objeto é rigorosamente idêntico ao do filme de ficção, e, por conseguinte, não constitui uma opção real frente a ele" (p. 406).

Decorrentes dos apontamentos de Salles e Omar, abordamos os exercícios do olho e do olhar mais no contexto educativo das narrativas audiovisuais ou curtas-metragens, como propõe Moletta (2014), do que dos documentários, pois este último situa-se na polêmica fronteira ficção/não fiç̧ão. Além disso, o próprio conceito de ficção tem abordagens diversas no pensamento contemporâneo e, de maneira breve, apresentamos um deles, tributário de Michel Foucault, e do qual nos aproximamos. Foucault afirmou que escreveu somente ficções: 
Com isso, não quero dizer que estejam fora da verdade. Parece-me possível fazer a ficção trabalhar na verdade, induzir efeitos de verdade com um discurso ficcional e, de algum modo, fazer com o que o discurso de verdade suscite, fabrique alguma coisa que ainda não existe, portanto "ficcione". "Ficciona-se" a história a partir de uma realidade política que a torna verdadeira, "ficciona-se" uma política que ainda não existe a partir de uma verdade histórica. (FOUCAULT, 1994 [1977, p. 193] apud RODRIGUES, 2007, p. 44).

Essa noção mobilizou-nos, permitindo que os/as estagiários/as produzissem as narrativas audiovisuais nas escolas mais como potências que fraturam/abalam, mesmo em filigranas, discursos naturalizados acerca delas próprias, do que como falta, ausência de potência de vida. Para Bondia (2002, p. 21), "a experiência é o que nos passa, o que nos acontece, que nos toca. Não o que se passa, não o que acontece, ou o que toca”.

Essa ideia de experiência, à qual se refere o autor, condiz com o que esperávamos que ocorresse com os/as estagiários/as durante o período de estágio obrigatório nas escolas de ensino fundamental. Assim, ao acompanhar as atividades desenvolvidas nas escolas, ao observar as várias dimensões envolvidas nas interações de sala de aula, nossa expectativa era de que algo acontecesse com os estagiários, que algo se passasse com eles de maneira que pudessem, de fato, viver experiências que contribuíssem com sua transformação de estagiários de licenciatura. Esperávamos, pois, que os/as estagiários/as fossem "sujeitos da experiência" o que, segundo o autor mencionado, se define como um "território de passagem, algo como uma superfície sensível que aquilo que acontece afeta de algum modo, produz alguns afetos, inscreve algumas marcas, deixa alguns vestígios, alguns efeitos" (BONDIA, 2002, p. 24).

Para alguns/mas professores/as em formação, as atividades de estágio, por si sós, possibilitaram experiências, uma vez que, por características pessoais, essa abertura já estava presente neles/as. Entretanto, para outros/as, foram necessários diferentes estímulos para que se tornassem sujeitos da experiência, uma vez que estavam habituados/as com a superficialidade das informações e a rapidez com que as coisas acontecem (BONDIA, 2002). A solicitação de que os/as estagiários/as produzissem uma narrativa audiovisual possibilitou que todos/as vivenciassem, além das experiências proporcionadas pelas observações nas escolas, outra experiência transformadora que é dada pelo próprio processo de produção de narrativas audiovisuais.

Assim, para atender à solicitação de produzir um registro audiovisual acerca de algum aspecto relativo às interações de sala de aula observadas na escola de estágio, os/as professores/as em formação, antes de tudo, fizeram escolhas e tomaram decisões, exigindo que refletissem com mais profundidade acerca do vivido para, a partir daí, criarem sua própria narrativa. Esse processo inseriu-se na dimensão da educação do olhar, uma vez que se associou às experiências que os/as estagiários/as vivenciaram no dia a dia da escola e que os afetou, interferindo diretamente nessas escolhas. Mas esse processo também se relacionou com a educação do olho na medida em que exigiu dos/ das estagiários/as apropriações e recriações das realidades observadas ao expressarem, por meio de sequências de imagens, sons e textos, um produto único, de sua autoria, 
possibilitando a própria transformação e, por vezes, a transformação de seus/suas colegas que, ao se depararem com essa outra realidade, poderiam, também, viver experiências.

$\mathrm{Na}$ acepção da educação do olho, o que mais nos interessou investigar foi o modo como as narrativas audiovisuais foram produzidas pelos/as estagiários/as ao revelarem-se como experiências tanto no que se refere à sua origem (observações de aulas na escola básica) como no que diz respeito ao processo pelo qual são produzidas, processo este que é, por si só, uma experiência. Tanto em relação à educação do olho quanto à educação do olhar, procuramos compreender como as escolhas e experiências dos/as estagiários/ as refletem e são refletidas na construção de suas identidades docentes, ou seja, como as narrativas audiovisuais relacionam-se com a formação dos/as professores/as.

Parte do cronograma da disciplina de estágios foi organizada de modo a contemplar a preparação dos/das estudantes-estagiários/as para produzir imagens, de preferência em movimento, sobre interações ocorridas em situações de sala de aula. Com base nesses audiovisuais, nossa expectativa foi a de que, por meio da linguagem cinematográfica, os/as referidos/as estudantes-estagiários/as apresentassem outros jeitos de dizer e dar a ver acerca do contexto escolar, apontando potências por meio de filigranas daquilo que, habitualmente, é considerada a realidade escolar.

Esta pesquisa é parte de uma investigação maior que envolveu a coleta e decupagem dos audiovisuais produzidos na disciplina no ano de 2012. Do total de 21 audiovisuais produzidos, analisamos as linguagens visual, verbal e sonora e selecionamos três narrativas. Essa seleção decorreu da peculiaridade na forma como os/as estudantes-estagiários/as lidaram com os adensamentos do ato de ensinar, em contextos formais de educação, por meio de sua apresentação em uma linguagem que não lhes é usual em contexto de formação de professores, qual seja, a cinematográfica.

A referida peculiaridade diz respeito à priorização do uso das linguagens corporais ${ }^{4}$ pelos/as estudantes-estagiários/as para apresentar suas experiências com a produção de narrativas audiovisuais, evidenciando também e, principalmente, outros modos de estar no contexto escolar, frequentado agora tanto na condição de estagiários/as como em uma ambiência formativa. Essas várias dimensões do estar na escola proporcionou aos/ às referidos/as estudantes e-ducar o olhar de outro modo que diz respeito não a qualquer coisa ou de qualquer jeito, mas, sim, e-ducar o olhar por meio de deslocamentos operados entre a resistência e as possibilidades de transtornar hábitos educativos no modo de compreender a escola como espaço de formação - de alunos/as, de professores/as, de professores/as em formação inicial, de inspetores/as, de cozinheiras/os, de faxineiras/os etc. - e espaço de formação de sensibilidades.

As linguagens corporais ou gestos educativos estão, necessariamente, entranhados em nós. Entendemos o ser humano e sua corporeidade como "naturalmente o lugar das

4- Entendidas aqui como gestos educativos forjados na relação entre professores, alunos e contextos escolares; e tributárias de "uma descoberta do corpo como objeto e alvo e poder" (FOUCAULT, 1999 [1995, p. 136], p. 117), em meados do século XVIII. Essa investida no corpo emerge sincronicamente com a emergência das disciplinas: "[...] é o momento em que nasce uma arte do corpo humano, que visa não unicamente 0 aumento de suas habilidades, nem tampouco aprofundar sua sujeição, mas a formação de uma relação que no mesmo mecanismo 0 torna tanto mais obediente quanto é mais útil, e inversamente" (FOUCAULT, 1999 [1995, p. 137-138], p. 119). 
imagens" (BELTING, 2014, p. 79), natural no sentido de "um órgão vivo para imagens [...]" (p. 79). Assim:

[...] todos os aparelhos e dispositivos que hoje empregamos para armazenar e exportar imagens, e ainda que supostamente estes dispositivos ditem normas, o ser humano continua a ser o lugar em que se recebem e interpretam imagens num sentido vivo (portanto efêmero, dificilmente controlável, etc.). (BELTING, 2014, p. 79).

As linguagens corporais imbricaram-se com as escolhas imagéticas e com a montagem realizada pelos/as estagiários/as, as quais agenciaram contingências a escolhas estéticas, pois o rol das regras do jogo incluía negativas referentes à filmagem do corpo inteiro, principalmente os rostos. Regras estas que, expostas após o início do processo, bagunçaram os roteiros iniciais das filmagens. Coube aos/às estagiários/as compor com estratégias e linguagens, privilegiando partes dos corpos e outros modos de dar a ver o contexto escolar onde estagiaram, fosse por meio da filmagem das mãos, fosse por meio da colagem de máscaras nos rostos dos/das alunos/as videografados/as, desacostumando nosso repertório visual, muitas vezes cristalizado em determinados tipos de tomadas cinematográficas e fotográficas.

Procuramos identificar como os/as estagiários/as tomaram decisões, via linguagem audiovisual, para encaminhar questões como o cuidado de preservar a identidade dos/ das sujeitos/as envolvidos/as no contexto escolar e outras dificuldades técnicas. Ademais, a aposta em uma educação do olho e uma educação do olhar, conforme apresentado na introdução desse texto, foi imiscuída nesses audiovisuais selecionados, rompendo, mesmo que em filigranas, com a filosofia da representação platônico-cristã ${ }^{\text {, da }}$ qual somos tributários/as, principalmente quando se tratou de realizar esse tipo de experimentação em um curso de licenciatura que, de modo geral, está atado à referida filosofia.

Nossa pretensão foi menos apresentar metodologias de como lidar com o cinema e mais provocar movências no pensamento sobre o que pode o cinema em um curso de formação de professores/as de ciências, cuja área de saber tem na linguagem visual um de seus alicerces. E, nesse caso, o que pode o cinema na interface com a educação? Nos dizeres de César Leite e Rafael Christofoletti (2015, p. 40): "indicar possibilidades de montagens de sentidos", na medida em que os modos de enquadrar, editar, "olhar, ver e se afetar implicam práticas políticas de gestão da vida, de controle da existência ao criar modos de ver, olhar, sentir e ser na vida”. (LEITE; CHRISTOFOLETTI, 2015, p. 42). Nisso reside a imbricação de uma educação do olho com uma educação do olhar. A primeira vinculada à emergência da cultura visual, partícipe da constituição de uma educação visual que se

\footnotetext{
5- Entendemos esse registro de pensamento como atrelado a uma estética de cunho representativo que busca correspondências entre a imagem produzida via linguagem audiovisual e as respectivas analogias no que os/as estagiários/as concebem como realidade escolar, sobrelevando tentativas de espelhamento com o real para produzir e mostrar uma verdade das coisas que acontecem na escola. Diálogos pormenorizados acerca da filosofia da representação platônico-cristã podem ser encontrados, especialmente, nos escritos dos filósofos Miguel Spinelli (2003) e Bento Silva Santos (2003). Em Deleuze, a arte e a filosofia, de Roberto Machado (2009), há uma parte dedicada somente à interpretação deleuziana da filosofia de Platão, qual seja, "O nascimento da representação". No Vocabulário de Foucault, Edgardo Castro (2009) apresentou o verbete "Platão" para dizer de dois textos que Foucault se ocupou: Político e Alcebíades. Do primeiro "para marcar a oposição conceitual entre duas formas de exercício do poder, o político e o pastoral” (CASTR0, 2009, p. 321); e do segundo para tratar do cuidado de si.
} 
quer planetária, subjetivando-nos ordinariamente a mediar nossa relação com as coisas do mundo via produção, profusão e dispersividade de uma dada ordem visual e imagética. A segunda, por sua vez, relaciona-se mais ao governo do olhar, com seus gestos estéticos que parecem mover nossos corpos por diferentes topografias, no entanto, sem deslocar o pensamento e, por conseguinte, modos de vida, petrificando jeitos homogeneizadores de olhar para as rugosidades das geografias, necessariamente intempestivas.

\section{Da educação do olho e do olhar nas narrativas audiovisuais}

\section{Parte I: mãos como mapas de nossas rugosidades intempestivas}

[...] desenhadas na palma da mão, espalmada desde o nascimento pelo correr dos anos, as linhas da vida explicitam para quem as souber ler: coração, cabeça, vida e destino. E revitalizam subjetivamente a energia vermelha do equador. A mão, sua palma sova a massa enquanto os dedos abertos procuram alcançar o que está além do horizonte geográfico e humano brasileiro. Mãos, linhas, cores. Eis o mapa do mundo tal como se torna ao alcance da artista Adriana Varejão e das imagens que produz. (SANTIAGO, 2011) ${ }^{6}$.

Ao entrevistar, na escola básica, professores, professoras, alunos e alunas que não autorizaram a gravação de seus rostos, a solução encontrada por uma das estagiárias foi enquadrar somente as mãos por meio de um plano detalhe enquanto eles/as discorriam, um a um, sobre a pergunta dela: "Qual o seu sentimento na sala de aula"? No início de seu curta-metragem, a estagiária escolheu enquadramento de câmera em ângulo alto, inserindo nosso olhar no corredor cimentado que dava acesso às dependências da escola para, em seguida, redirecionar o olhar do espectador para um portão (aberto), a partir do qual a sequência de imagens nos levava a conhecer outros espaços da escola.

A partir dessas informações é interessante destacar a escolha de enquadramentos: ângulo aberto (long shot) e ângulo contrário ao da cena inicial (contra-plongée), respectivamente. Ao fazer essa escolha, a estagiária desloca nosso imaginário acerca do que venha a ser a instituição escolar com suas salas de aula, quadras poliesportivas, entre outros elementos. Interessante observar a diversidade de pares de mãos. Algumas “terminam em segredo" (PESSOA, 2002, p. 20), outras são solteiras e esmaltadas. Há aquelas que se assemelham a mapas, cujas linhas são as da vida.

As reflexões realizadas por nós acerca do primeiro dos três curtas-metragens selecionados dizem respeito incialmente às escolhas (estética e política) de sua autora, remetendo-nos à palestra de Silviano Santiago, principalmente, ao afirmar que seus interesses de estudos e reflexões têm se voltado para objetos artísticos simples como, por exemplo, o corpo humano e a mão. 0 escritor e ensaísta refere-se a várias obras artísticas que também o inspiraram, uma delas (figura 1) a da artista plástica brasileira Adriana Varejão:

6- Excerto da conferência de Silviano Santiago proferida em 12/11/2011, no Delicate Seminar, realizado na Princeton University. Disponível em: $<$ https://vimeo.com/42441658>. Acesso em 10 dez. 2017. 
Figura 1 - Fotografia linotipia Contingente (2000)*, de Adriana Varejão.

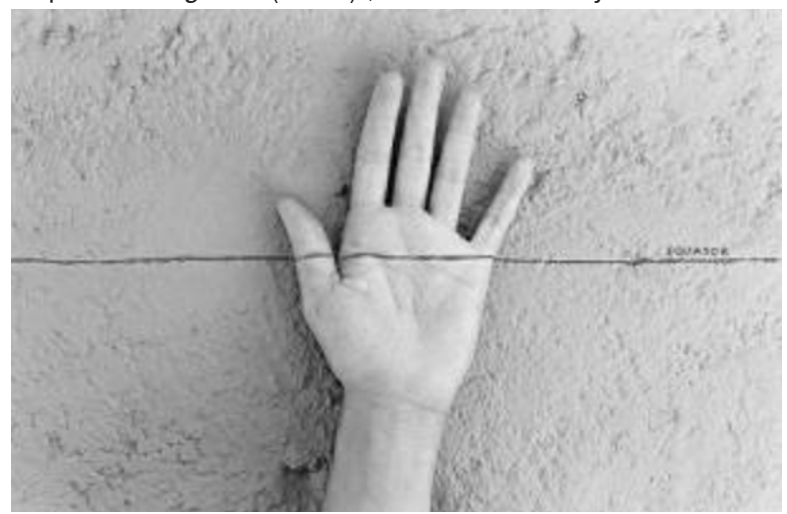

*Fonte: Fotografia: 28x40.5cm (edição de 5) 22x32.6cm (edição de 100). Disponível em: <http://www.adrianavarejao.net/pt-br/category/categoria fotografias>. Acesso em 10 dez. 2017.

\section{Santiago diz:}

Da própria mão contra a parede Adriana tira uma foto como se aparelhada por olhos de geógrafa e de adivinha. Ali ela primeiro suplementa as linhas traçadas pela vida com uma linha vermelha ao meio nomeada Equador. A linotipia nos remete a imagem cartográfica do mundo subjetivamente densa e forte já que sem alusão aos pequenos e objetivos cubículos onde se desenham os nomes dos continentes e das nações. (SANTIAGO, 2011). ${ }^{7}$

Assim como Santiago, ao editar sua narrativa audiovisual, Patrícia ${ }^{8}$ afirma, em entrevista, que as mãos são mapas de nossas rugosidades - fruto das experimentações, seja quando se opta por um modo fraco de vida, seja quando se opta por um modo forte. De acordo com ela:

Dos professores entrevistados [...] há aqueles que ficaram com as mãos completamente estáticas sobre a mesa, como se, com suas mãos, não fossem se expor, mas se expuseram. Quando a imagem das mãos funde-se com a oralidade é como se a rugosidade do corpo inteiro se apresentasse no movimento (ou não movimento) impetrado pelas mãos: dos sufocos, das angústias e, principalmente, dos desejos de professores/as e alunos/as que nunca se encontram no espaço da sala de aula: dos/das professores/as de ensinar e dos/das dos/as alunos/as de aprender. ${ }^{9}$

Durante a entrevista, entre uma reflexão e outra com Patrícia acerca das mãos e de suas rugosidades, dos encontros entre alunos e alunas, professores e professoras -

\footnotetext{
7- Excerto da conferência de Silviano Santiago proferida em 12/11/2011, no Delicate Seminar, realizado na Princeton University. Disponível em: <https://vimeo.com/42441658>. Acesso em 10 dez. 2017.

8- A estagiária autorizou-nos o emprego de seu nome.

9- Excerto de transcrição da entrevista realizada com a estagiária no dia 28/05/2015.
} 
sujeitos cujos corpos foram, são e continuam fortemente marcados pela cultura escolar -, a autora do audiovisual relatou-nos também acerca da dificuldade de narrar, por meio do audiovisual, a acomodação dessas diferentes gerações e suas trajetórias nos processos de construção dos saberes e não-saberes de professores/as e alunos/as. De acordo com ela, há um estrangulamento dos processos educativos quando a tríade desejo-potênciatransgressão deixa de ser produzida nas brechas de uma educação majoritária. Como dizer isso empregando a linguagem audiovisual? Exercício difícil e complexo, conforme excerto dos dizeres da estudante:

$\mathrm{Na}$ universidade estamos mais acostumados com a linguagem escrita. No dia-a-dia somos solicitados por grande quantidade de imagens, ao mesmo tempo, que produzimos uma parte delas, ao menos para as pessoas que têm acesso aos meios para isso. Produzir um audiovisual, por mais tosco que possa parecer não é tarefa simples, afınal, exige a obtenção de um extenso repertório de imagens (sejam elas estáticas ou em movimento) e sons. A produção de um filme e, neste caso, um curta metragem, somente concretiza-se quando a gente começa a editar/ficcionar o repertório imagético, seja ele qual for. ${ }^{10}$

Eis as escolhas estéticas, políticas e poéticas da estagiária que, de um mergulho no cimento da entrada da escola, nos dá a ver um espaço utilizado de outra maneira: a manutenção de árvores extremamente altas, dedução passível de ser realizada em decorrência da escolha do ângulo contra-plongée. Seus galhos e folhas são penetrados com luz solar, riscando o plano do enquadramento. Lembramo-nos, nesse momento, de quando "um fotógrafo-artista nos disse: Veja que pingo de sol no couro de um lagarto é para nós mais importante do que o sol inteiro no corpo do mar" (BARROS, 2010, p. 109). Isso é fruto de um duplo movimento: a educação do olhar e a educação do olho.

Nesse sentido, "a importância de uma coisa há que ser medida pelo encantamento que a coisa produza em nós” (BARROS, 2010, p. 109). Ou seja, os enquadramentos e a edição realizados por Patrícia em seu audiovisual são frutos de escolhas deliberadas, mas também de uma educação visual mais ampla em curso, com a finalidade de atualizar virtualidades.

Informações, saberes e expectativas precisam ser deixados na porta de entrada, e o cartógrafo deve pautar-se sobretudo numa atenção sensível, para que possa, enfım, encontrar o que não conhecia, embora já estivesse ali, como virtualidade. (KASTRUP, 2009, p. 48-49).

E o que estagiária não conhecia? 0 que se passou com Patrícia durante seu estágio e que se revelou por meio da apresentação das mãos dos professores daquela escola?

Embora não tenhamos a resposta sobre $o$ que se passou, não há dúvidas de que algo se passou com ela e, certamente, contribuiu com sua formação como professora.

Os espaços escolares e os sujeitos da escola não passaram despercebidos a essa estagiária e seu modo de nos dizer isso evidencia que ela pensou sobre a escola e sobre a

10- Excerto de transcrição da entrevista realizada com a estagiária no dia 28/05/2015. 
profissão docente. Com que mãos Patrícia se identificou? Haveria mãos que poderiam, de fato, dar a ver sua expectativa acerca de seu próprio trabalho docente?

Não objetivamos responder a estas perguntas, mas, por meio delas, reafirmar, mais uma vez, que a formação da identidade docente é um processo contínuo, já que essa identidade se transforma ao longo de toda vida. Assim, as transformações que ocorreram com Patrícia ao elaborar o audiovisual compõem apenas uma pequena parte desse percurso.

\section{Parte II: Encontros com a autora como motivação para a leitura}

A segunda narrativa audiovisual sobre a qual nos detivemos apresentou um recorte muito interessante e envolvente sobre uma sequência didática realizada em aulas da disciplina de língua portuguesa em que alunos/as de $6^{\circ}$ ano se envolveram com a leitura de um livro, os preparativos para um contato com a autora durante sua visita à escola e alguns momentos posteriores a isso.

As estagiárias apropriaram-se da linguagem oral narrativa como estratégia para apresentar o contexto e aproximar o espectador de uma realidade da escola apresentada no vídeo, apropriando-se de alguns elementos do livro de literatura como a protagonista da história e o título do livro que compôs parte do título do vídeo.

Antes de analisarmos essa narrativa visual, cabe mencionar um fato que antecedeu sua elaboração: em uma das aulas da disciplina de estágio, as estagiárias procuraram a docente mencionando não saber o que fazer, pois não dispunham de muitos recursos tecnológicos, não tinham conhecimentos acerca de como editar vídeos e não tinham muitas autorizações para a divulgação das imagens dos/as alunos/as da escola básica. A docente respondeu que as estagiárias deveriam soltar a imaginação e exercitar sua criatividade, de modo que sua narrativa fosse contada da melhor forma possivel, apesar das dificuldades.

A libertação da imaginação, estimulada pela docente, parece ter feito muita diferença no resultado final, uma vez que, a partir daí, as estagiárias revelaram-se seguras e motivadas a preparar o audiovisual. Um dos aspectos interessantes acerca dos preâmbulos da elaboração da narrativa audiovisual refere-se a mais um elemento importante na cultura escolar: o papel do docente na regulação das ações dos/as alunos/as, o que nos remete ao texto de Lazzarato (2013), ao analisarmos este episódio sob a ótica da enunciação. Por meio da autorização da professora, as estagiárias produzem uma enunciação na forma de dizer verdadeiro (parresia), uma vez que:

[...] não supõe nenhum status, ela é a enunciação de "não importa quem". Diferentemente dos performativos, ela "abre-se a um risco indeterminado", "possibilidade, campo de perigos, ou, pelo menos, eventualidade não determinada”. (LAZZARATO, 2013, p. 305 [2014, p. 234]).

Ademais, a liberação da professora parece ter evidenciado às estagiárias que suas vivências (de observação e de elaboração do audiovisual) eram valorizadas no contexto acadêmico em que se encontravam, o que as estimulou a mergulharem na experiência expressiva a que estavam sendo solicitadas. A partir desse momento, a elaboração do audiovisual tornou-se realmente uma experiência (BONDIA, 2002), visto que elas se 
permitiram viver intensamente o processo de produção criativa e apresentar o que lhes aconteceu a partir da experiência de estágio e que pôde ser ressignificado com a elaboração do vídeo.

A aceitação do desafio de abrir-se para o risco indeterminado de produzir um enunciado de própria autoria, estar à mercê das próprias produções imaginais, usando os audiovisuais como meios para essa enunciação imagético-verbal, permitiu que as estagiárias construíssem um sentido próprio àquilo que observaram e vivenciaram na escola.

Para Vygotsky (2000), a função criadora ou combinadora do cérebro consiste na criação de algo novo a partir das experiências passadas (registradas na memória), ou seja, a produção criativa ocorre por meio da recombinação de elementos da realidade, o que faz surgir uma realidade particular e única. Assim, não esperamos com este trabalho analisar a visão que as estagiárias tiveram da realidade, mas, sim, conhecer essa nova realidade que é a narrativa audiovisual e as revelações que ela apresenta acerca de como a identidade docente dessas duas futuras professoras está constituindo-se.

Hans Belting (2014) aponta para o fato de que o meio (suporte) pelo qual as imagens são produzidas e difundidas é, ao mesmo tempo, instituidor de reais. A partir disso não se pode deixar de mencionar a importância que teve para as alunas a exigência de que o meio que deveriam utilizar para produzir sua enunciação deveria ser o audiovisual e não outro. A busca de conexão entre narração, apresentação de imagens fotográficas, filmagens e texto escrito ficou evidente ao longo de todo audiovisual elaborado.

0 fato de haver grande quantidade de fotografias em que os/as alunos/as aparecem com seus rostos cobertos - recurso utilizado para superar o problema da falta de autorização dos responsáveis para a divulgação das imagens - não comprometeu a mensagem, uma vez que foi possível visualizar o tipo de atividades realizadas por eles/as, os modos como as carteiras estavam expostas, os materiais que estavam sendo utilizados e as posturas dos corpos. Nas situações em que os rostos ficaram descobertos, as expressões faciais levam o espectador à impressão de que os/as alunos/as estão motivados/as e alegres.

No vídeo aparece o depoimento de uma aluna da escola básica enfatizando seu contentamento no encontro com a autora. 0 depoimento da professora, por sua vez, revela que, mesmo quando suas expectativas relativas ao comportamento dos alunos não foram atendidas, a ocasião da visita da autora foi um evento de grande importância e satisfação para os/as alunos/as e para ela. É interessante pensar, também, sobre a preocupação das autoras do audiovisual de, dentre todas as observações realizadas na escola, destacar aspectos que consideraram abalos problematizadores da ambiência essa instituição.

0 estágio possibilitou-lhes vivenciar uma experiência prazerosa e frutífera de observação de como a professora mediou aspectos importantes da cultura letrada, tais como ler, interpretar, pensar sobre o que foi lido, elaborar questões, além, é claro, do momento da visita em que os/as alunos/as puderam interagir diretamente com a autora. Ao enfatizar a motivação vivenciada por professora e escolares, as estagiárias revelaram, também, sua própria motivação: divulgar um trabalho bem-sucedido, dando crédito à professora, que, neste momento, ocupa um lugar que em breve poderá ser ocupado pelas próprias estagiárias. 
Considerando que o período de estágio consiste em uma etapa importante para a formação dos/as futuros/as professores/as, parece-nos que os resultados dessa experiência, explicitados por meio do audiovisual, indicam aspectos da formação inicial da identidade docente das estagiárias. Ao contrário de outros vídeos em que encontramos tons de denúncia e crítica às falhas encontradas na escola (não analisados neste trabalho), este revela uma visão positiva de escola e de trabalho docente. A edição feita pelas estagiárias produzindo carinhas felizes pode indicar a crença de que é possível realizar um bom trabalho na escola pública quando há empenho do/a professor/a em motivar os/as alunos/ as e organizar as atividades de modo significativo e motivador.

Mencionando a análise de pinturas faciais rituais de diferentes culturas analisadas por Lévi-Strauss, Belting (2014, p. 49) enfatiza que "apenas por meio do mascaramento o rosto se converte no portador social de signos, cuja função executa”. Ainda que a natureza das máscaras utilizadas pelas estagiárias para cobrir os rostos dos alunos seja completamente diferente das máscaras rituais, acreditamos que se possa fazer um paralelo entre elas enquanto portadoras sociais de signos que, neste caso, referem-se a um ideal de escola feliz, ao menos no que diz respeito às interações entre professor/a, alunos/as e conhecimentos abordadas no vídeo. Assim, os corpos biológicos dos/as alunos/as que foram decapitados de identidade, pois suas faces não podiam ser mostradas, ganham identidade dentro da enunciação tornando-se corpos sociais plenos de significados.

Ainda segundo Belting (2014, p. 51):

[...] a representação do sujeito está intimamente ligada à questão da máscara que este enverga, portanto, com a da imagem que essa máscara projeta. A máscara é simultaneamente meio e entidade imaginal, de tal forma que o nosso olhar se revela incapaz de os distinguir na imagem que produzem.

Os corpos dos/as alunos/as revestidos pelas máscaras criadas pelas estagiárias tornam-se, ao mesmo tempo, a própria entidade imaginal de escola feliz e o meio de veiculação dessa ideia.

\section{Parte III: A escrita e o desenho entrelaçados na narrativa audiovisual}

A terceira narrativa audiovisual analisada neste trabalho abordou um projeto desenvolvido pela professora de inglês da escola, que aproveitava os conteúdos da disciplina escolar de ciências para abordar o aprendizado da língua inglesa. 0 audiovisual alterna imagens de trabalhos interdisciplinares com o projeto de Inglês para o $4^{\circ}$ ano do ensino fundamental I. Nos trechos da aula da professora com o grupo de alunos/as selecionados é evidente a importância atribuída pelas estagiárias às estratégias de movimento corporal da professora regente do projeto na associação do vocabulário da língua inglesa às ações de movimento, expressas pelos verbos ditos por ela no decorrer da aula.

A escolha desse foco, pelas autoras do audiovisual, decorreu do encantamento provocado pela experiência vivenciada por elas junto a essa professora, que conseguia vencer a resistência dos/as alunos/as e implicar a todos, inclusive às estagiárias, no 
processo de aprendizagem. Esse encantamento pode ser traduzido na legenda que as alunas atribuíram ao vídeo. Para elas, o projeto destacou-se por romper com a ideia de "educação bancária" (FREIRE, 1996) e se aproximar de um ideal de aprendizagem participativa que compõe uma situação almejada dentro da formação da identidade docente dessas estagiárias.

Sobreposta às imagens de trabalhos dos/as alunos/as do conteúdo curricular de ciências, compostas por imagens de conceitos trabalhados e vocábulos na língua inglesa, há o entrelaçamento entre a representação de conceitos abordados na forma de desenhos e escrita na língua inglesa com os movimentos corporais da professora, que atribuíram significados aos novos vocábulos aprendidos pelos/as alunos/as. Todos esses entrelaçamentos de meio, corpo e imagem são enredados ainda pela linguagem escrita que as estagiárias acrescentam na forma de legenda do audiovisual: "0 projeto de Inglês (extracurricular) tem como intuito despertar o interesse dos alunos, não apenas para o ensino de inglês, mas funciona como um estímulo tanto para as matérias regulares como para a vida".

Esse estímulo para a vida, a que as alunas se referem, está presente em outras partes do audiovisual, na medida em que elas buscam palavras e imagens associadas à participação, ao vínculo entre os participantes, aos sentimentos: a palavra dedicação acompanha como legenda um determinado momento da aula da professora gestora do projeto; a palavra compromisso acompanha como legenda um determinado momento do depoimento do coordenador pedagógico da escola; as palavras vínculo e amor são selecionadas pelo coordenador pedagógico para expressarem em "uma palavra" a importância do projeto para a escola.

Toda essa construção imagética corrobora com a ideia de analogia entre corpos e meios de Belting $(2014$, p. 36), no sentido que a fabricação de imagens é afetada pela evolução da imagem mágica até a representação racional do mundo, de forma que:

\footnotetext{
À imagem adere uma tal obscuridade que só pode ser vencida pela luz de uma reflexão ilustrada: nesta evolução, o que havia sido imagem em sentido arcaico, clarificar-se-ia ou como linguagem (com o seu uso de símbolos e metáforas) ou como arte.
}

Para o autor é necessário romper com a ideia de retorno à crença nas imagens introduzindo-se uma antropologia histórica como metodologia de investigação de meios e símbolos culturais empregados na produção da própria imagem. Assim, além do entrelaçamento de meio, imagem e corpo, acrescentam-se os laços da sonoridade pela escolha da música Oito anos, de Adriana Partimpim ${ }^{11}$, que acompanha a apresentação de imagens de painéis e os trechos do audiovisual em que alternam diversas imagens.

Da escolha da música aos enquadramentos dos/as participantes em movimento e interação, as autoras procuram levar o/a espectador à ideia de uma escola que transforma vidas mais do que uma escola que transmite conteúdos. Para nós, essa escolha reflete a formação da identidade docente já discutida em Dominguez et al. (2015). A busca por uma escola transformadora e o papel do/a professor/a nisso aparecem, de forma marcante,

11- Disponível em: <http://www.adrianapartimpim.com.br/um/> 
tanto nas narrativas apresentadas no trabalho de Dominguez et al. (2015) como no discurso audiovisual produzido pelas estagiárias.

Pelo enfoque do audiovisual produzido pelas estagiárias a escola deixa de ser um espaço catedrático e hierarquizado para tratar o aprendizado de forma horizontal, produzindo interações e vínculos entre os/as alunos/as e a professora. A professora de inglês não deixa de assumir o papel de protagonista no processo de aprendizagem e conduz os alunos nas atividades, liderando a aula. Porém, esse protagonismo se faz de forma fluida, não imposta por uma hierarquização de poder entre professor/a e aluno/a, mas realizado por alguém - a professora - que é ciente e segura de seu papel e que, como tal, estabelece-se naturalmente como condutora do processo.

Como lembra Lazzarato (2013, p. 316 [2014, p. 246]):

[...] ocupar-se de si mesmo, realizar um trabalho sobre si e sobre sua própria vida significa cuidar das maneiras de fazer e de dizer necessárias para ocupar o lugar que nos é atribuído na divisão social do trabalho.

No audiovisual esse "cuidar das maneiras de fazer e de dizer" aparece como linhamestra do trabalho da professora que inspira as estagiárias. Essa inspiração liga-se ao ideário de docente que as estagiárias trazem, do ser professor/a como agente transformador, do/a professor/a que participa da vida dos alunos pela criação de vínculos afetivos e que, assim, os leva a um novo patamar de vida, como ilustrado pela legenda final do audiovisual:

0 desenvolvimento deste projeto proporciona a participação mais ativa e positiva dos alunos, tanto na sala de aula como fora dela!

0 trabalho demonstra que com pequenos gestos conseguimos transformar um futuro próximo!

Assim, há coerência entre as imagens apresentadas e as palavras que elas utilizam nas legendas na construção de uma imagem positiva do trabalho docente, na possibilidade de transformação que o/a professor/a tem sobre a vida dos/as alunos/as e na construção da identidade docente das estagiárias.

\section{Considerações finais}

Não procuramos, nesta investigação, avaliar o que ocorreu na escola de educação básica em si, mas o que dessa experiência de estágio de observação de sala de aula foi revelado por meio dos audiovisuais produzidos. Nos vídeos analisados, a escola é apresentada de forma mais potente, particularmente nas duas últimas narrativas audiovisuais, o que se destaca do recorrente discurso que comumente aparece nas discussões iniciais nas disciplinas de estágio, desvalorizando as ações pedagógicas observadas nas escolas acerca do ato de ensinar.

A solicitação de que os estagiários e estagiárias produzissem uma narrativa audiovisual possibilitou que eles/as vivenciassem, além das experiências proporcionadas 
pelas observações nas escolas, outra experiência proporcionada pela elaboração de narrativas audiovisuais, reforçando nossa hipótese inicial de que quando se muda o tipo de linguagem empregada na produção discursiva altera-se a educação do olhar via educação do olho, cuja diferença foi amplamente explicitada no início desse texto. Essas vivências são possibilitadas pela própria linguagem audiovisual, pois esta altera o jeito de olhar, recortar e enquadrar as situações que, supostamente, nos são familiares. Cabe mencionar que a limitação de tempo de vídeo proporcionou, também, um importante exercício de síntese. A necessidade de escolher as imagens e construir narrativas condizentes com o tempo determinado estimulou a reflexão sobre como articular textos, imagens e sons para a realização de um vídeo que revelasse o que eles/as pensavam sobre a escola observada.

As três narrativas audiovisuais, selecionadas por nós, decorreram de uma preferência estética dos/das estagiários/as, qual seja, lentes mirando linguagens corporais (empregadas pelos/as professores/as das escolas de educação básica), inaderentes a processos de desescolarização - apologia, diga-se de passagem, bastante difundida nos dias atuais ${ }^{12}$. Nesse sentido, a referida escolha dos/as estudantes-estagiários/as interessou-nos, no contexto da licenciatura, porque topografias invisíveis dessas ambiências tiveram a chance de ganhar visibilidade plástica por meio da linguagem audiovisual. Invisíveis, não porque essas topografias inexistam, mas, justamente pelo contrário: invisiveis porque nosso olhar está deveras acostumado a ver, enxergar e entender o mundo mediado por discursos asfixiados e imagens clichês esgotadas, em decorrência de uma repetição, supostamente inventiva, desses mesmos discursos e imagens; tal como em loops desgastados, mesmo quando vertidos em tonalidades e sonoridades de promessas inovadoras.

A discussão do trabalho da Patrícia permite explorar bem as metáforas do olho e do olhar e da experiência. A educação do olho reflete-se nas escolhas feitas pela estagiária na busca de suas imagens: uma vez que não lhe foi permitida a captura das imagens dos rostos, Patrícia procurou outra parte do corpo que, a despeito de não revelar a identidade pessoal dos/as entrevistados/as, revelou-lhes a personalidade por meio dos gestos capturados nos movimentos das mãos. Por outro lado, as reflexões evidenciadas na narrativa de Patrícia indicam a construção do seu processo de educação do olhar, na medida em que ela pensa sobre sua própria formação docente ao observar o movimento das mãos e suas linguagens. Assim, as ideias sobre o que é a instituição escolar e seus atores vão sendo repensadas pela estagiária durante a construção da sua narrativa audiovisual. Indícios da transformação da sua própria identidade docente ficam registrados nas escolhas imagéticas e nas falas verbais e corporais dos entrevistados.

Já as duas últimas narrativas direcionam o olhar e a experiência vivida para o que há de potente na escola. Isso é nítido no segundo audiovisual em que a noção de experiência positiva da visita da autora à instituição está impressa nas máscaras felizes que recobrem os rostos dos/as alunos/as. 0 olhar das estagiárias volta-se para o que há de vigoroso nas ações pedagógicas, refletindo as próprias expectativas do que pode ser o trabalho docente. A experiência escolhida para a construção da narrativa audiovisual

12- Vide Quando sinto que já sei, documentário brasileiro de 2014. Em Aquino (2017), encontrar-se-ão críticas oportunas tanto ao documentário quanto à apologia da desescolarização. 
das estagiárias evidencia um desejo de que a escola funcione, seja palco de vivências significativas, revelando a própria expectativa que elas têm do ser professor/a e, assim, interferindo na construção das suas identidades docentes.

No terceiro audiovisual, por sua vez, a educação do olho apresenta-se por meio da seleção de textos escritos e desenhos, da observação dos movimentos do corpo da professora e da própria escolha da música para compor uma experiência bem-sucedida de ação pedagógica. Já a educação do olhar, revelada pelas legendas que acompanham a construção da narrativa, mostram, como no segundo audiovisual, uma expectativa de positividade nas relações e ações pedagógicas. A ideia de professor/a transformador/a aparece em toda a narrativa, revelando o ideário de professor/a já discutido no processo de construção da identidade docente em Dominguez et al. (2015).

Acreditamos que a imersão no ambiente educacional, possibilitada pela permanência das estagiárias numa mesma escola durante mais de um semestre e meio até o momento de produção do audiovisual, possibilitou aos/às estudantes-estagiários/as desnaturalizar as concepções do que possa ser a escola pública a partir das experiências dessas estagiárias. De acordo com Lazzarato (2013 [2014]), a formação do sujeito constituise pela palavra e pela razão articuladas às práticas discursivas. Portanto, a construção da narrativa audiovisual das estagiárias se faz em direção ao que elas viveram nas escolas, bem como à criação de espaçamentos educativos outrora obstruídos, ao invés de buscarem a escola e professor/a ideais.

\section{Referências}

ALMEIDA, Milton José de. Imagens e sons: a nova cultural oral. São Paulo: Cortez, 2004.

AQUINO, Julio Groppa. Defender a escola das pedagogias contemporâneas. ETD - Educação Temática Digital, Campinas, v. 19, n. 4, p. 669-690, out./dez. 2017. Disponível em: <https://periodicos.sbu.unicamp. br/ojs/index.php/etd/article/view/8648729/16858>. Acesso em: 10 set. 2017.

BARROS, Manoel de. Sobre desimportâncias. In: BARROS, Manoel de. Memórias inventadas: as infâncias de Manoel de Barros. São Paulo: Planeta do Brasil, 2010. p. 107-109.

BELTING, Hans. Antropologia da imagem. Tradução de Artur Morão. Lisboa: KKYM + EAUM, 2014.

BONDIA, Jorge Larrosa. Notas sobre a experiência e o saber de experiência. Revista Brasileira de Educação, Rio de Janeiro, n. 19, p. 20-28, abr. 2002. Disponível em: <http://www.scielo.br/pdf/rbedu/n19/n19a02. pdf $>$. Acesso em: 15 out. 2017.

CASTRO, Edgardo. Vocabulário de Foucault: um percurso pelos seus temas, conceitos e autores. Tradução de Ingrid Müller Xavier. Belo Horizonte: Autêntica, 2009.

DELEUZE, Gilles. Francis Bacon: lógica da sensação. Tradução Aurélio Guerra et al.; coordenação de tradução Roberto Machado. Rio de Janeiro: Zahar, 2007. 
DOMINGUEZ, Celi Rodrigues Chaves et al. Professional choices and teacher identities in the Science Teacher Education Program at EACH/USP. Cultural Studies of Science Education, v. 10, n. 4, p. 1189-1213, Dec. 2015.

DUBAR, Claude. A socialização: construção das identidades sociais e profissionais. Tradução de Andréa Stabel M. Da Silva. São Paulo: Martins Fontes, 2005.

FOUCAULT, Michel. A arqueologia do saber. Tradução de Luiz Felipe Baeta Neves. 8. ed. Rio de Janeiro: Forense Universitária, 2013 [1972].

FOUCAULT, Michel. Power/knowledge. New York: Pantheon Books, 1977.

FOUCAULT, Michel. Vigiar e punir: nascimento da prisão. Tradução de Raquel Ramalhete. 20. ed., Petrópolis: Vozes, 1999 [1995].

FREIRE, Paulo. Pedagogia do oprimido. Rio de Janeiro: Paz e Terra, 1996.

KASTRUP, Virgínia. Pista 2: o funcionamento da atenção no trabalho do cartógrafo. In: PASSOS, Eduardo; KASTRUP, Virgínia; ESCÓSSIA, Liliana (Org.). Pistas do método da cartografia: pesquisa-intervenção e produção de subjetividade. v. 1. Porto Alegre: Sulina, 2009. p. 32-51.

LAZZARATO, Maurizio. Enunciação e política: uma leitura paralela da democracia - Foucault e Rancière. In: BRANCO, Guilherme Castelo; VEIGA-NETO, Alfredo (Org.). Foucault: Filosofia \& política. Belo Horizonte: Autêntica, 2013. p. 299-318. (Estudos foucaultianos).

LAZZARAT0, Maurizio. Signos, máquinas e subjetividades. Tradução de Paulo Domenech Oneto com a colaboração de Hortência Lencastre. São Paulo: SESC: n-1, 2014.

LEITE, César Donizetti Pereira; CHRISTOFOLETTI, Rafael. Pra quê cinema? 0 que pode o cinema na educação e a educação no cinema? Fronteiras de encontros. In: FRESQUET, Adriana (Org.). Cinema e educação: a Lei 13.006 - reflexões, perspectivas e propostas. v. 1. Belo Horizonte: Universo Produção, 2015. p. 40-50.

MACHADO, Roberto. Deleuze, a arte e a filosofia. Rio de Janeiro: Zahar, 2009.

MASSCHELEIN, Jan. E-ducando o olhar: a necessidade de uma pedagogia pobre. Educação \& Realidade, Porto Alegre, v. 33, n. 1, p. 35-47, 2008. Disponível em: <http://seer.ufrgs.br/index.php/educacaoerealidade/ article/view/6685/3998>. Acesso em: 10 set. 2017.

MIRANDA, Carlos Eduardo Albuquerque. Uma educação do olho: as imagens na sociedade urbana, industrial e de mercado. Caderno Cedes, Campinas, v. 21, n. 54, p. 28-40, ago. 2001. Disponível em: $<$ http://repositorio.unicamp.br/bitstream/REPOSIP/32366/1/S0101-32622001000200004.pdf>. Acesso em: 10 set. 2017.

MOLETTA, Alex. Fazendo cinema na escola: arte audiovisual dentro e fora da sala de aula. São Paulo: Summus, 2014. 
OMAR, Arthur. 0 antidocumentário, provisoriamente. Revista de Cultura Vozes, Petrópolis, v. 72, n. 6, p. 405-418, ago. 1978.

PESSOA, Fernando. Cancioneiro. São Paulo: L\&PM, 2002.

RANCIĖRE, Jacques. 0 espectador emancipado. Tradução de Ivone C. Benedetti. São Paulo: WMF Martins Fontes, 2012. [2009]

RODRIGUES, Heliana de Barros Conde. Michel Foucault, as "marcas da pantera" e a "pantera cor-de-rosa": apontamentos sobre o processo de desinstitucionalização psiquiátrica. Vivência, Natal, n.32, p. 41-60. 2007.

SALLES, João Moreira. A dificuldade do documentário. In: MARTINS, José de Souza; ECKERT, Cornélia; NOVAES, Sylvia Cainby. 0 imaginário e o poético nas ciências sociais. São Paulo: Edusc, 2005. p. 57-71.

SANTOS, Bento Silva. Platonismo e cristianismo: irreconciabilidade radical ou elementos comuns? Veritas, Porto Alegre, v. 48, n. 3, p. 323-336, 2003.

SPINELLI, Miguel. Platonismo cristão? Que platonismo? Boletim do CPA, Campinas, n. 15, p. 157-168, jan./ jun. 2003. Disponível em: <http://www.puc-rio.br/parcerias/sbp/pdf/16-miguelr.pdf>. Acesso em: 05 out. 2017.

TARDIF, Maurice. Saberes docentes e formação profissional. Petrópolis: Vozes, 2002.

VYGOTSKY, Lev Semyonovich. La imaginación y el arte en la infancia. Madrid: Akal, 2000.

Recebido em: 11.12.2016

Revisões em: 23.06.2017

Aprovado em: 25.10.2017

Valéria Cazetta é docente da Escola de Artes e Ciências Humanas (EACH) da Universidade de São Paulo (USP).

Celi Rodrigues Chaves Dominguez é docente da Escola de Artes e Ciências Humanas (EACH) da Universidade de São Paulo (USP).

Fabiana Curtopassi Pioker-Hara é educadora da licenciatura em Ciências da Natureza da Escola de Artes e Ciências Humanas (EACH) da Universidade de São Paulo (USP).

Josely Cubero é educadora da licenciatura em Ciências da Natureza da Escola de Artes e Ciências Humanas (EACH) da Universidade de São Paulo (USP). 